\title{
Brote comunitario de influenza A H1N1 2009 en el período post-pandémico inmediato: descripción epidemiológica en una localidad aislada de la región de Aysén, Patagonia chilena
}

\author{
Sebastián Layera R., Nicolás Fontena C., Edgardo Rojas T., Marco Acuña B. y Paola Saldivia U.
}

Hospital Dr. Leopoldo Ortega Rodríguez de Chile Chico. Región de Aysén. (SLR, NFC, ERT, PSU). Secretaría Regional Ministerial de Salud de Aysén (MAB).

Conflictos de Interés: Autores no declaran ningún conflicto de interés.

Fuente de financiamiento: No declaran.

Recibido: 6 de enero de 2011 Aceptado: 6 de mayo de 2011

Correspondencia a: Sebastián Layera Ramos sebastianlayera@gmail.com

\author{
Epidemiologic description of a post-pandemic outbreak of influenza A H1N1 \\ 2009 in an isolated community of the region of Aysén, \\ Chilean patagonia
}

On August $10^{\text {th }} 2010$ the World Health Organization (WHO) announced the end of the influenza A H1N1 2009 pandemic. On August 13 ${ }^{\text {th }}$, three cases of influenza A H1N1 2009 from the local school were confirmed at the Hospital de Chile Chico. An epidemiological investigation was conducted in conjunction with the regional health authority (SEREMI), in order to monitor the outbreak and establish appropriate control strategies. During the study period (august 7 to 21), 304 cases of influenza-like-illness (ILI) were reported, with an incidence of 6171 cases per 100.000 in epidemiological week $n^{\circ} 33$. Most of the affected people were 19 years old or younger (68\% of cases). Hospitalized patients (n: 7) had a favorable outcome, without severe symptoms or need for transfer to an intensive care unit. A female patient with a congenital heart defect who had not been vaccinated was the only fatal case. The outstanding features of this post-pandemic outbreak were its intensity and the demonstration of the importance of control measures to prevent further spread of influenza A H1N1 2009 infections, in the community setting.

Key words: Disease outbreak, influenza A virus H1N1 subtype, pandemic, community.

Palabras clave: Brote infeccioso, virus influenza A subtipo H1N1, pandemia, comunidad.

\section{Introducción}

$\mathrm{D}$ esde el primer reporte en Chile de infección por el virus de la influenza A H1N1 2009, realizado en mayo de $2009^{1}$, hasta el 31 de diciembre del mismo año se reportó un total de 368.118 casos de enfermedad tipo influenza (ETI) definida por el Ministerio de Salud como: fiebre mayor a $38,5^{\circ} \mathrm{C}$ axilar y tos, asociado a alguno de los siguientes síntomas: mialgias, odinofagia o cefalea, confirmándose por RPC en tiempo real 12.302 casos, de los cuales 132 fallecieron ${ }^{2}$.

Durante el año 2010 al igual que en el resto de los países del hemisferio sur, se esperaba una nueva ola pandémica que afectaría durante los meses de invierno a todo el territorio nacional ${ }^{3}$, por lo cual el ministerio de salud mantuvo el nivel de alerta epidemiológica en todos los centros de salud del país y realizó una campaña de vacunación masiva contra influenza A H1N1 2009, centrándose en los grupos de riesgos identificados durante el 2009 y en el personal de salud.

En agosto de 2010, el Director General de la OMS afirmó que la pandemia por influenza A H1N1 2009, iniciada en abril del año 2009, había entrado en la fase post-pandémica. Se esperaba que el virus tomara una conducta similar al de la influenza estacional, ya que los reportes actuales evidenciaban que los brotes producidos primariamente por el virus pandémico mostraban una intensidad similar a la observada durante epidemias estacionales ${ }^{4}$.

El objetivo de este trabajo es describir un brote por virus influenza A H1N1 2009 durante el período postpandémico inmediato en una localidad geográficamente aislada de la undécima Región de Chile, de una magnitud similar a la observada en el resto del país durante el año 2009.

Contexto geográfico y epidemiológico. La localidad de Chile Chico se encuentra ubicada en la región de Aysén, distante $1.777 \mathrm{~km}$ al sur de Santiago y a $402 \mathrm{~km}$ de la capital regional, Coyhaique. Está situada geográficamente en la ribera sur del Lago General Carrera (el segundo lago más grande de Sudamérica), al este de la cordillera de Los Andes y a $3 \mathrm{~km}$ de la frontera con Argentina. Cuenta con 3.808 habitantes urbanos y cerca de 400 habitantes rurales en sus proximidades. El clima es frío en comparación al resto del país, con temperaturas que oscilan en invierno 
entre $-10{ }^{\circ} \mathrm{C}$ y $5{ }^{\circ} \mathrm{C}$ y precipitaciones que no sobrepasan los $300 \mathrm{~mm}$ al año. El único centro de salud de la localidad es el Hospital Dr. Leopoldo Ortega Rodríguez, que cuenta con cuatro médicos generales y dos enfermeras, además de otros profesionales que integran el equipo de salud básico, para una dotación de 15 camas indiferenciadas, de baja complejidad.

Durante el año 2009 el número de casos de ETI reportados en la región de Aysén fue de 2.450 con una tasa máxima de 162 por 100.000 habitantes durante la semana epidemiológica 26, cifra cercana al promedio nacional ${ }^{2}$. Mientras que en Chile Chico solamente se informaron 37 casos de ETI durante todo el año, concentrándose los casos en el grupo etario de 20 a 60 años. Se registró un caso que requirió hospitalización, en un paciente de 19 años portador de un daño pulmonar crónico y que evolucionó favorablemente con tratamiento antiviral.

Entre mayo y junio del año 2010 se efectuó una campaña de vacunación masiva en el país contra influenza A H1N1 2009 dirigida a los grupos de riesgo determinados por el Ministerio de Salud de Chile: niños entre 6 y 23 meses, mujeres embarazadas con más de 13 semanas de gestación, pacientes con enfermedades crónicas y adultos de 65 y más años. La población estimada a vacunar en Chile Chico por grupos de riesgo era de 876 personas, lográndose una cobertura de 95,7\% (838 vacunados) al 15 de junio de 2010.

\section{Descripción del brote}

El día 10 de agosto de 2010 (semana epidemiológica 32) se identificó en el servicio de urgencia del hospital un número inusual de casos compatibles con la definición de $\mathrm{ETI}^{5}$, presentándose en cinco niños, dos adultos y un lactante de 1 año 4 meses. Se confirmó un nexo epidemiológico entre los menores, ya que asistían a clases en el mismo curso, siendo los adultos contactos domiciliarios de los primeros. Ese mismo día, en la escuela básica se registró la inasistencia de 56 menores y comenzó a observarse en el servicio de urgencia un aumento exponencial en el número de consultas por causa respiratoria, mayoritariamente por ETI y, especialmente, en el grupo etario de 5 a 14 años. Se procedió a notificar inmediatamente el brote de ETI a la autoridad sanitaria regional (SEREMI), la cual decidió enviar a un epidemiólogo para caracterizar el brote, además de proveer de insumos diagnósticos para identificar el agente causal. El día 13 de agosto se realizó aspirado nasofaríngeo a cuatro casos con diagnóstico clínico de ETI, enviándose al laboratorio del Hospital Regional de Coyhaique, por vía aérea, donde mediante inmunofluorescencia directa se testearon las muestras para detección de virus respiratorios (virus respiratorio sincicial, adenovirus, parainfluenza e influenza A y B), dando como resultado tres de cuatro muestras positivas para influenza A, que posteriormente fueron enviadas según protocolo ${ }^{5}$ al Instituto de Salud Pública (ISP), confirmándose por RPC-TR en tiempo real la presencia de influenza A H1N1 2009 en las tres muestras examinadas.

Inmediatamente luego de notificar el brote se decidió por parte del equipo de salud local implementar medidas para disminuir los contagios en la comunidad y en el hospital. A nivel comunitario se realizó una campaña comunicacional vía radios locales y medios escritos para educar a la población sobre las medidas de prevención del contagio, además de realizar charlas educativas en el jardín infantil, escuela y liceo, lugares donde se había identificado el mayor número de casos consultantes por ETI. Con el objeto de disminuir la posibilidad de contagio masivo se decidió, en conjunto con las autoridades comunales, suspender las clases en la escuela y jardín infantil, así como también se postergaron todas las actividades comunitarias que involucraran aglomeración de personas en lugares cerrados.

A todos los pacientes con diagnóstico clínico de ETI se les indicó reposo, aislamiento domiciliario durante 5 días y profilaxis para los contactos de riesgo, además de proveerles mascarillas desechables en caso necesario. En el hospital se suspendieron las atenciones de pacientes crónicos, se implementó el triage para separar consultantes por causa respiratoria y no respiratoria, atendiéndose por separado en lugares distantes dentro del mismo establecimiento. El registro de la información de los datos de atención de urgencia fue recopilado diariamente e ingresado a una planilla computacional del programa Excel $^{\circledR}$, logrando monitorizar de forma diaria la evolución del brote infeccioso.

Producto de la investigación epidemiológica, pudo establecerse que el caso índice fue un escolar de 6 años que consultó el 7 de agosto en el servicio de urgencia, con el antecedente de haber estado durante los días previos en la ciudad de Coyhaique (capital regional). El paciente cursó con un cuadro leve que se manejó de forma ambulatoria con antipiréticos y no requirió de tratamiento antiviral. Al día siguiente, a tres compañeros de curso del caso índice se les diagnosticó ETI y fueron enviados a domicilio con tratamiento sintomático. Durante los días posteriores se produjo un aumento exponencial del número de consultas por patología respiratoria, siendo la mayoría de los casos ETI, alcanzando un máximo de 71 pacientes al día y 235 durante la semana epidemiológica 32. Entre el 7 y 21 de agosto se contabilizaron 439 consultas por síndrome gripal, gripe o ETI, constituyendo este último diagnóstico el 69\% (304) del total (Figura 1).

La distribución por grupos etarios evidenció que durante la primera semana del brote los casos se concentraron entre los 5 y 14 años (62\%), alcanzando una media de 13 años y con un rango etario entre los 8 meses 
Figura 1. Número de consultas diarias por diagnóstico de ETI, gripe o síndrome gripal (n: 429). Hospital de Chile Chico, 7 al 21 de agosto de 2010.

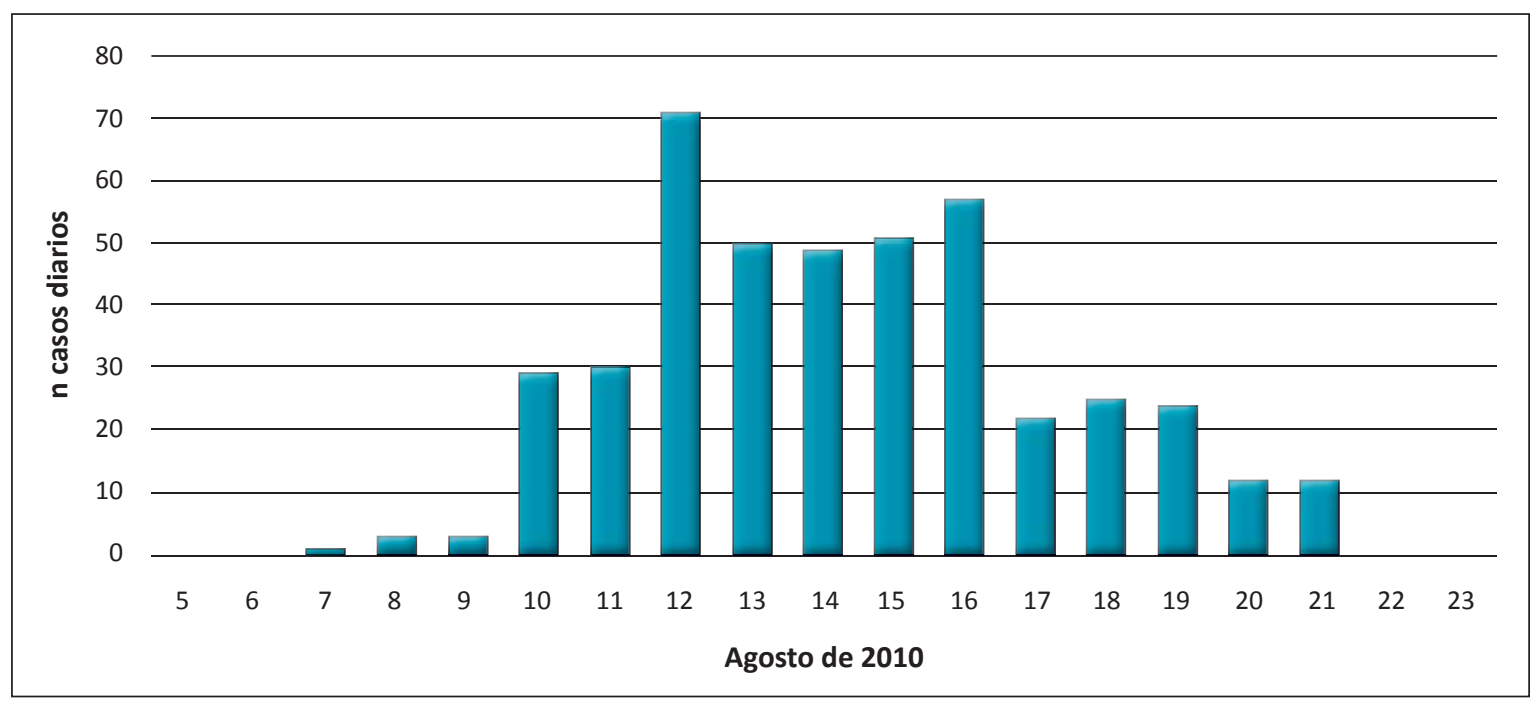

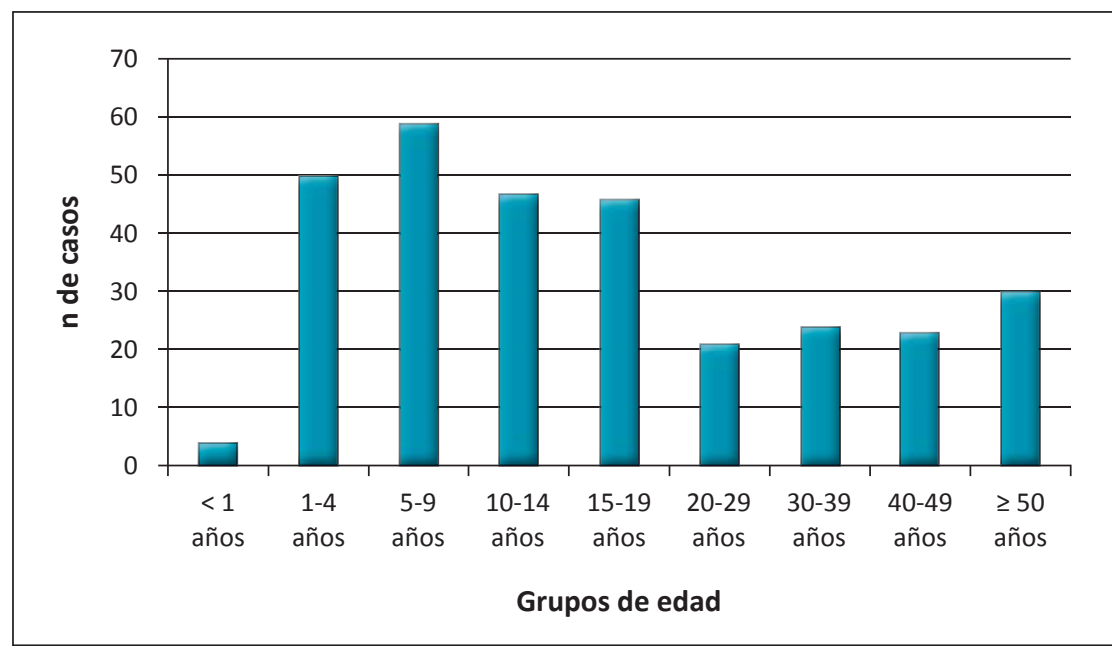

Figura 2. Número de consultas por ETI según grupo etario entre 7 al 21 de agosto de 2010.

Tabla 1. Pacientes hospitalizados, con criterios de gravedad, entre el 7 al 21 de agosto de 2010

\begin{tabular}{|cllll|}
\hline Fecha & Edad & Sexo & Diagnóstico & Co-morbilidad \\
\hline $18 / 08$ & 97 años & Femenino & Neumonía & Insuficiencia cardíaca, HTA \\
$19 / 08$ & 69 años & Masculino & ETI & Insuficiencia cardíaca, HTA \\
\hline $19 / 08$ & 18 años & Masculino & Neumonía & No \\
$19 / 08$ & 7 meses & Masculino & ETI & SBOR \\
\hline $19 / 08$ & 73 años & Femenino & Neumonía & Diabetes mellitus \\
\hline $20 / 08$ & 44 años & Femenino & Neumonía & No \\
\hline 20/08 & 22 años & Masculino & ETI & No \\
\hline $\begin{array}{l}\text { ETI: enfermedad tipo influenza. HTA: hipertensión arterial. SBOR: síndrome bronquial obstructivo } \\
\text { recurrente. }\end{array}$ & & & \\
\hline
\end{tabular}

y 75 años. Posteriormente, se observó un aumento de los casos en adolescentes y niños bajo 5 años, concentrando los pacientes bajo 19 años el 68\% del total. La media se desplazó hacia los 20 años y se reportó un mayor número de ETI en adultos y adultos mayores (Figura 2).

El 97,6\% de los casos de ETI fueron leves y se manejaron de forma ambulatoria con antipiréticos y reposo en domicilio. Un 34,5\% (n: 104) recibieron tratamiento antiviral con oseltamivir y zanamivir (mujeres embarazadas), de los cuales 86 fueron por ETI en pacientes con condiciones de riesgo definidas en la guía clínica ${ }^{6}$, mientras que 11 pacientes recibieron profilaxis por ser contacto de un caso de ETI y presentar factores de riesgo. Durante el brote se registraron siete casos que requirieron hospitalización por presentar criterios de gravedad al ingreso (Tabla 1), seis de los cuales requirieron oxígeno adicional al ingreso o durante la hospitalización; de éstos, cuatro tenían alguna co-morbilidad. Todos recibieron tratamiento antiviral y fueron manejados en camas de baja complejidad, sin necesidad de ser trasladados al hospital regional.

El único fallecimiento ocurrido en el período estudiado correspondió a una paciente de sexo femenino de 42 años, con antecedentes de cardiopatía congénita, sin control médico, y que no recibió vacuna contra influenza A H1N1 2009 por no acudir al hospital durante la campaña de vacunación. La paciente consultó el 16 de agosto en forma tardía, luego de tres días con un cuadro febril, tos y disnea de reposo en domicilio, y que ingresó al servicio de urgencia con compromiso de conciencia, rigidez de nuca e insuficiencia respiratoria. Evolucionó rápidamente con shock y falla multiorgánica y sin respuesta a las maniobras de reanimación, falleciendo cuatro horas después de su ingreso. Ese mismo día se gestionó la asistencia de un anatomo-patólogo desde el 
hospital de Coyhaique, realizándose la autopsia in situ, que entregó como causa de muerte un shock séptico secundario a una bronconeumonía, además del hallazgo de una estenosis valvular aórtica. Se tomaron muestras de tejido pulmonar que posteriormente fueron enviadas al ISP, donde se confirmó mediante RPC-TR la presencia de infección por influenza A H1N1 2009.

\section{Discusión}

La magnitud de la pandemia por el virus de la influenza humana A H1N1 en Chile durante el año 2009 fue significativa respecto de la mayoría de los países del hemisferio sur, contabilizando un alto número de casos de influenza clínica y de casos confirmados por RPC-TR; no obstante, la tasa de letalidad registrada durante el año 2009 se ubicó dentro de las más bajas en el concierto mundial7, resaltando la capacidad de respuesta del sistema de salud chileno ante eventos epidemiológicos inesperados y de impacto global.

El comportamiento del virus influenza A H1N1 2009 en el país, durante el 2009, fue relativamente homogéneo en las distintas regiones del territorio ${ }^{2}$, registrándose diferencias menores en la tasas de incidencia y de letalidad por el virus. Esta distribución de casos se observó fundamentalmente en las grandes ciudades, lo que se contrapone a lo ocurrido en localidades más pequeñas del país, cuyo aislamiento geográfico explicaría, en parte, el menor número de casos por influenza A H1N1 2009 registrado durante el 2009.

Durante el año 2010, según el reporte hasta la semana epidemiológica 47 (21 al 27 de noviembre de 2010), se observó en Chile un aumento del número de casos de ETI en la semana 31, destacando la circulación paralela de influenza A H1N1 2009, H3N2 e influenza B. Los casos confirmados por el virus influenza A H3N2 triplicaron en número a los casos por influenza A H1N1, lo cual es consecuente con la conducta esperada para éste durante el período post-pandémico ${ }^{8}$. A nivel regional, los primeros casos confirmados por influenza B e influenza A H3N2 se registraron durante la primera semana de agosto de 2010 en Coyhaique, casi tres semanas después del inicio del brote en Chile Chico, observándose el resto del año un comportamiento del virus influenza similar al resto del país, con predominio del subtipo estacional.

La localidad de Chile Chico constituye un objeto de estudio epidemiológico óptimo, ya que alberga una población pequeña aislada del resto del país y de la región, la cual tiene un solo centro prestador de salud (pública y privada), permitiendo un registro adecuado de la información generada en brotes de enfermedades infecciosas, con una medición inmediata del impacto de las medidas tomadas para su mitigación.
El brote por influenza A H1N1 2009 ocurrido en la localidad de Chile Chico durante el mes de agosto de 2010 destaca por su magnitud, comparable e incluso mayor a lo observado durante el año de inicio de la pandemia en el resto del país, con una tasa de incidencia de 6.171 casos por 100.000 habitantes, registrada durante la semana epidemiológica 32, y con una tasa de ataque global de un $7,98 \%$ durante todo el brote.

El predominio de los casos ambulatorios en el grupo entre los 0 y 19 años (68\%) es concordante con lo observado a nivel país durante el 2009, con una tasa de ataque de $14,8 \%$ para ese grupo etario, explicado en parte por la exposición masiva de los contactos al interior de los establecimientos educacionales de la comuna. Es necesario agregar que durante la primera ola pandémica del 2009 en Chile Chico, en la cual se registró un número muy reducido de casos, los estudiantes primarios y secundarios estaban en vacaciones de invierno, dejando probablemente un gran número de individuos susceptibles y que no tuvieron acceso a la vacunación por no corresponder a grupos de riesgo.

El número de casos de ETI que requirieron hospitalización fue reducido; no obstante, la tasa de hospitalización fue de 2,3\%, cifra similar a lo descrito en brotes de otras latitudes ${ }^{9}$. Destaca además que existió un predominio de pacientes añosos con presencia de co-morbilidades.

El único caso fatal registrado durante el brote es llamativo por la rápida evolución del cuadro, la presencia de síntomas neurológicos al ingreso y la nula respuesta a las maniobras de reanimación avanzada.

Es difícil estimar el efecto que tuvieron las medidas de mitigación en la comunidad, ya que la historia natural de esta enfermedad es de carácter autolimitado; sin embargo, sí es medible cualitativamente el efecto de la información y educación a la población usuaria, ya que se pudo percibir una disminución en el nivel de ansiedad y una baja considerable en el número de consultas en el servicio de urgencia por causas no respiratorias, lo cual probablemente tuvo un efecto no despreciable en el número total de casos por influenza A H1N1 2009.

Este estudio demuestra, a un año de la declaración de la pandemia, que todavía es posible observar brotes comunitarios por influenza A H1N1 2009 con intensidades similares a las del año 2009. Lo más probable en este caso descrito es que haya ocurrido una acumulación de individuos susceptibles, planteamiento fundamentado en el bajo número de casos registrado durante el año de ocurrencia de la pandemia.

Es menester agregar que el aislamiento geográfico, la falta de recursos diagnósticos y terapéuticos, no deben ser obstáculos para realizar estudios epidemiológicos exhaustivos en hospitales de baja complejidad, pero se requiere de una red de salud integrada y motivada para emprender dichas tareas. 


\section{Resumen}

El 10 de agosto de 2010 la Organización Mundial de la Salud (OMS) declaró el fin de la pandemia por el virus influenza A H1N1 2009. El 13 de agosto, se confirmaron tres casos de influenza A H1N1 2009 en el Hospital de Chile Chico provenientes de la escuela local. Se inició una investigación epidemiológica en conjunto con la autoridad sanitaria regional (SEREMI) para monitorizar la evolución del brote y para implementar medidas de prevención y mitigación del contagio. Durante el período de estudio (7 al 21 de agosto) se registraron 304 casos de enfermedad tipo influenza (ETI), alcanzando una incidencia durante la semana epidemiológica 33 de 6.171 casos por 100.000 habitantes. Los menores de 19 años fueron el grupo etario más afectado (68\% de los casos). Los pacientes que requirieron hospitalización (n: 7) evolucionaron favorablemente y ninguno requirió traslado a una unidad de cuidado intensivo. Sólo se consignó un caso fatal durante el brote, en una paciente con co-morbilidad cardiaca y sin vacuna. Este brote infeccioso destaca por su intensidad en el contexto del período post-pandémico e ilustra sobre la importancia de las medidas de prevención del contagio por influenza A H1N1 2009 a nivel comunitario.

\section{Referencias}

1.- Ministerio de Salud de Chile: Informe sobre la situación de la infección por nueva influenza A (H1N1) en Chile 2009. Disponible en: http:// www.redsalud.gov.cl/portal/url/item/6dd4341b 4fecb8a1e04001011f01440c.pdf. Acceso el 30 octubre de 2010.

2.- Ministerio de Salud de Chile: Influenza pandémica (H1N1) 2009. Reporte de situación 2009, 13 de Enero de 2010. Disponible en http:/www.pandemia.cl/templates/pandemia/ documentos/Informe_13_enero.pdf. Acceso el 30 de octubre de 2010.

3.- World Health Organization. Preparing for the second wave: lessons from current outbreaks. Disponible en: http://www.who.int/csr/disease/ swineflu/notes/h1n1_second_wave_20090828/ en/index.html. Acceso el 30 de octubre de 2010.
4.- $\quad$ World Health Organization. WHO recommendations for the post-pandemic period. Disponible en: http://www.who.int/ csr/disease/swineflu/notes/briefing_20100810/ en/index.html. Acceso el 30 de octubre de 2010.

5.- $\quad$ Ministerio de Salud de Chile. Departamento de Epidemiología. Circular n²0 "Influenza estacional y pandémica (H1N1): Vigilancia epidemiológica, investigación y control de brotes”. Disponible en: http://www.pandemia. cl/templates/pandemia/documentos/circular_ num_20.pdf. Acceso el 30 de octubre de 2010.

6.- Ministerio de Salud de Chile: Guía Clínica para el Diagnóstico y Manejo Clínico de Casos de Influenza Pandémica (H1N1) 2009. Version 4.0 abril 2010. Disponible en: http://www. pandemia.cl/templates/pandemia/documentos/
Guia_Clinica_Caso2010_v_280410.pdf. Acceso el 30 de octubre de 2010

7.- $\quad$ Swedish K A, Conenello G, Factor S H. First season of 2009 H1N1 influenza. Mt Sinai J Med 2010; 77 (1): 103-13.

8.- Ministerio de Salud de Chile: Informe de influenza 30 de noviembre de 2010. Disponible en: http://www.pandemia.cl/ templates/pandemia/documentos/Informe_ influenza_30_11_2010.pdf.

9.- Chilean Task Force for Study of Pandemic Influenza A (H1N1), Pedroni E, García M, Espínola V, Guerrero A, González C, Olea A, et al. Outbreak of 2009 pandemic influenza A(H1N1), Los Lagos, Chile, April-June 2009. Euro Surveill. 2010;15(1):pii=19456. Disponible en: http://www.eurosurveillance.org/ ViewArticle.aspx?ArticleId=19456. Acceso el 30 de octubre de 2010. 